\title{
Impact of a Pre-Professional Clinical Education Experience with Adults with Autism Spectrum Disorder: Preparation of Future Speech-Language Pathologists
}

\author{
Kaitlyn P. Wilson Ph.D., CCC-SLP \\ Towson University, kwilson@towson.edu \\ Gregory S. Chasson Ph.D. \\ Towson University and Illinois Institute of Technology, gchasson@iit.edu \\ Amanda C. Jozkowski Ph.D., OTR/L \\ Towson University, ajozkowski@towson.edu
}

See next page for additional authors

DOI: doi.org/10.30707/TLCSD1.2Wilson

Follow this and additional works at: https://ir.library.illinoisstate.edu/tlcsd

Part of the Speech Pathology and Audiology Commons

\section{Recommended Citation}

Wilson, Kaitlyn P. Ph.D., CCC-SLP; Chasson, Gregory S. Ph.D.; Jozkowski, Amanda C. Ph.D., OTR/L; and Mulhern, Meghan V. Ed.M. (2017) "Impact of a Pre-Professional Clinical Education Experience with Adults with Autism Spectrum Disorder: Preparation of Future Speech-Language Pathologists," Teaching and Learning in Communication Sciences \& Disorders: Vol. 1: Iss. 2, Article 5.

DOI: doi.org/10.30707/TLCSD1.2Wilson

Available at: https://ir.library.illinoisstate.edu/tlcsd/vol1/iss2/5

This Scholarship of Teaching and Learning Research is brought to you for free and open access by ISU ReD: Research and eData. It has been accepted for inclusion in Teaching and Learning in Communication Sciences \& Disorders by an authorized editor of ISU ReD: Research and eData. For more information, please contact ISUReD@ilstu.edu. 


\title{
Impact of a Pre-Professional Clinical Education Experience with Adults with Autism Spectrum Disorder: Preparation of Future Speech-Language Pathologists
}

\begin{abstract}
The purpose of this study was to (1) investigate the impact of a clinical experience with adults with autism spectrum disorder (ASD) on graduate speech-language pathology (SLP) students' knowledge about ASD, and (2) explore the nature of the clinical experience and its impact on students' preparation to work with adults with ASD. This study used a mixed-methods design. Quantitative methods were used to identify statistically significant changes in student knowledge about ASD following participation in a clinical experience with adults with ASD. Qualitative methods were used to explore student narratives to uncover details of the clinical experience and its impact. Participants $(n=17)$ were first year SLP master's students. Results indicate significantly increased knowledge about ASD following participation in the clinical experience with adults with ASD. Coding of themes from student narratives revealed details about key aspects of the experience and its impact. Results point to the positive impact of an immersive, groupbased clinical education experience with adults with ASD. Results may guide efforts to create programs to prepare clinicians to serve the growing population of adults with ASD. Next steps include comparison of similar clinical experiences, as well as longitudinal tracking of student outcomes.
\end{abstract}

\section{Keywords}

Autism spectrum disorder, adult, pre-professional preparation, speech-language pathology

\section{Cover Page Footnote}

This study is funded by a research award from the Hussman Center for Adults with Autism, made possible by funding from the Towson University Foundation. We would also like to acknowledge the qualitative analysis contributions of Talisa Thomas. Finally, we would like to thank the student participants and the staff of the Hussman Center for Adults with Autism for their role in supporting this study.

\section{Authors}

Kaitlyn P. Wilson Ph.D., CCC-SLP; Gregory S. Chasson Ph.D.; Amanda C. Jozkowski Ph.D., OTR/L; and Meghan V. Mulhern Ed.M.

This scholarship of teaching and learning research is available in Teaching and Learning in Communication Sciences \& Disorders: https://ir.library.illinoisstate.edu/tlcsd/vol1/iss2/5 


\section{Introduction}

Background. Based on current estimates, one in 68 children has an autism spectrum disorder (ASD) (Baio, 2014). Each year, approximately 50,000 youth with ASD in the United States exit high school and enter adulthood (Roux, Shattuck, Rast, Rava, \& Anderson, 2015). With the rising incidence of ASD (Baio, 2014) and the existing population of individuals on the autism spectrum advancing in age, there is a pressing need for clinical professionals trained and experienced to work with adults on the autism spectrum. This population presents unique characteristics and needs that often differ from those of children on the autism spectrum (Gotham et al., 2015; Turcotte, Mathew, Shea, Brusilovskiy, \& Nonnemacher, 2016) and those of adults with other developmental conditions (e.g., Loveland \& Kelley, 1988; Orsmund, Shattuck, Cooper, Sterzing, \& Anderson, 2013; Roux et al., 2015). Social and communication difficulties are central to the experience of individuals on the autism spectrum, regardless of age (Kanner, 1943); however, as individuals on the autism spectrum enter adulthood, social-communication needs relate more specifically to difficulty engaging in meaningful relationships (i.e., romantic relationships and friendships) and gaining and maintaining employment (Eaves \& Ho, 2008; Howlin \& Moss, 2012; Roux et al., 2015).

Individuals on the autism spectrum interact with a variety of professionals and community members throughout adulthood. Disconcertingly, studies show that many pre-professional students in health care disciplines, as well as practicing clinical professionals, lack even a basic understanding of diagnostic criteria for ASD (Freedman, 2014; Hartley-McAndrew, Doody, \& Mertz, 2014; Price, 2013). Moreover, college students in general (i.e., future peers, co-workers, potential friends) hold many misconceptions about ASD, often confusing the condition with other diagnoses such as learning disabilities (Gillespie-Lynch et al., 2015). The overwhelming lack of knowledge and understanding adults on the autism spectrum are likely to confront in their community and their therapeutic experiences is problematic. Indeed, increasing societal understanding and acceptance of ASD has been rated by adults on the autism spectrum and their caregivers as a top priority for future work in the field of ASD (Gotham et al., 2015).

The current study focuses on the pre-professional training needs of speechlanguage pathologists (SLPs) as essential clinical service providers for adults on the autism spectrum. The American Speech-Language-Hearing Association (ASHA, the profession's national professional and credentialing association) states that "speech-language pathologists play a critical role in the screening, 
assessment, diagnosis, and treatment of persons with ASD" (ASHA, n.d.). However, despite SLPs' training in typical and atypical development of language and social communication, research shows a lack of preparation and misconceptions about ASD among practicing professionals in this field (Schwartz \& Drager, 2008; Plumb and Plexico, 2013).

In the last decade, a small number of studies have investigated practicing SLPs' training and knowledge of ASD. Notable findings include SLPs' reported lack of academic coursework focused solely on ASD and lack of contact with persons on the autism spectrum as part of their graduate clinical preparation, with the vast majority of surveyed SLPs indicating they would have benefitted from additional coursework and training related to ASD prior to beginning their professional careers (Schwartz \& Drager, 2008; Plumb and Plexico, 2013). As evidence of this limited preparation, most participating SLPs surveyed in one study had limited understanding of ASD diagnostic criteria (Schwartz \& Drager, 2008). Notably, much of the research on SLPs' training in ASD has focused on needs as they relate to service provision for children on the autism spectrum (e.g., survey respondents were school-based SLPs in Schwartz \& Drager, 2008). Despite the lack of adult-focused research in the area of pre-professional SLP preparation, it is assumed that there is a similar, or potentially more significant, training need among SLPs serving adults on the autism spectrum. Indeed, there is a noted paucity of research related to the needs of and services for adults on the autism spectrum in general (Roux et al., 2015), suggesting a similar limitation in clinical knowledge and training in this area.

Clinical Education. Hands-on clinical education plays a significant role in the pre-professional training of SLPs. "Traditional" approaches to clinical education typically involve a 1:1 supervisor to student ratio, in which one supervisor oversees the clinical experience of one student clinician providing services to one client (Sheepway, Lincoln, \& Togher, 2011). In light of increased student numbers and changing expectations from the field for new SLP graduates, graduate programs have explored alternative or "non-traditional" approaches to clinical education (Sheepway et al, 2011). Some alternative models include collaborative or group supervision, in which the same supervisor provides supervision to two or more students at a time (Sheepway et al. , 2011). Initial research is underway to determine which model of clinical education might facilitate SLP student clinicians' learning related to ASD, with one study pointing to an apprenticeship model (includes modeling and collaborative problem solving) as a factor in increasing student clinicians' ASD-specific knowledge and skills (Donaldson, 2015). However, this research is in its infancy and is not 
specific to the unique needs of SLPs in their training to work with adults with ASD.

There is an existing body of literature on adult learning that points to the importance of the cycle of experience, reflection, thought, and action in educational programs (Kolb \& Kolb, 2009). This educational philosophy, often applied to the study and development of higher education practices, is designed to accommodate various learning styles in a meaningful and supportive learning space (Kolb \& Kolb, 2005). Core principles of experiential learning proposed by Kolb and Kolb (2005) include "making space for development of expertise" and "making spaces for acting and reflecting" (p. 208). A similar philosophy of adult education is proposed by Jarvis (2004), emphasizing practical knowledge gained through various means of learning, including through experience. Research from a number of allied health and education fields aligns with these philosophies, supporting the importance of positive contact, or experience, with individuals with disabilities during pre-professional training. For example, physical therapy students who participated in an eight-week experience with young adults with Down syndrome reported being more comfortable with and having more confidence in their abilities to work with persons with disabilities (Shields \& Taylor, 2014). Similarly, a survey of pre-service teachers found that those with teaching or working experiences with individuals on the autism spectrum had more positive views of the population than those with only indirect contact (Park, Chitiyo, \& Choi, 2010). These findings point to the need for pre-professional clinical training programs for SLPs that provide an opportunity for student clinicians to interact meaningfully with individuals on the autism spectrum to gain knowledge through experience. The broad spectrum of ASD would point to the need for experience with multiple individuals with ASD, as can be facilitated through a group-based (vs. one-on-one) clinical experience.

\section{Study Aims}

It is clear that that there is a need for more, and perhaps different, pre-professional training in ASD for SLPs. Research in this area is growing; however, there remains a troubling gap in the study of SLPs' training to serve the growing population of adults on the autism spectrum in particular. This study aims to investigate the impact of a unique, immersive, group-based clinical education experience with adults on the autism spectrum on graduate SLP students, with the following specific aims: (1) to quantitatively investigate change in graduate SLP student clinicians' knowledge about ASD following participation in the clinical education experience with adults on the autism spectrum; and (2) to qualitatively explore the nature of the clinical education experience and SLP student clinicians' 
self-perceptions of any changes in the following areas after participation in the clinical education experience: knowledge about ASD, self-efficacy as service providers for adults with ASD, openness to adults with ASD, and additional contact with adults with ASD.

\section{Method}

Clinical Experience. This study was conducted at a large, suburban university in the mid-Atlantic region of the United States. First-year students in the university's master's program in SLP were invited to participate in this study if they were assigned a clinical education experience at the university's Hussman Center for Adults with Autism (HCAA) during either the fall or spring semester of that year.

The HCAA was established in 2008 and is a university-based program with funding from private donors and a foundation, and further support provided through ongoing program fees. The HCAA was designed to support adults on the autism spectrum in leading meaningful and engaged lives by addressing the shortage of resources for this population and providing a range of programming. In addition, the HCAA provides service-learning experiences for university students, including undergraduate students in various programs and those enrolled in clinically-focused graduate programs, such as occupational therapy and SLP, to better prepare these students to work and engage with adults on the autism spectrum. By bringing together adults on the autism spectrum and university students, the HCAA seeks to promote reciprocal learning and a mutually rewarding experience.

The HCAA's philosophy is unique in its focus on strengths, assumed competency, and respect for adults as peers and contributing participants in the intervention process. A statement from the HCAA's program manager in a recent public radio interview encapsulates the HCAA's philosophy well (Sivak, 2016):

It's about giving people an opportunity to demonstrate what they can do...it's to find ways that they can show people that they are capable. We really want to find places that these adults can contribute. That's why it's not how significantly impacted you are or can you talk or not talk, it's what you can contribute and we want to find that place because that's where adults find their dignity.

Under the guidance of their clinical supervisors, SLP graduate student clinicians who were placed in the HCAA programs were tasked with supporting participants' language and social communication needs. The HCAA programs included in the current study met once a week for 90 minutes. There was an average of four to six graduate student clinicians assigned to each of three 
programs (two focused on social and communication skills, one on functional reading and reading comprehension/fluency), with an average of six to 10 adult participants with ASD per program. After working with their assigned participants to establish goals for the semester, student clinicians worked collaboratively to plan group activities. Student clinicians also had time to work individually with participants during each session.

The supervision model employed by the HCAA was group-based, with one certified and licensed SLP supervising each group of student clinicians. The supervising SLP observed 100\% of sessions, provided live modeling, offered collaborative problem-solving assistance, and met with the group of student clinicians for 30 minutes after each session to discuss progress, answer questions, and plan in a collaborative manner. Supervisors provided additional feedback based on student clinicians' clinical documentation (i.e., notes and reports) across the semester.

Design. The study used a mixed-methods design, drawing on a combination of quantitative and qualitative data. Using quantitative and qualitative methods complementarily allows researchers to capitalize on the strengths of both methods, and to gain a deeper understanding of what mechanisms may influence the efficacy of an intervention (Glogowska, 2011). Quantitative methods were used to identify any statistically significant changes in student clinicians' knowledge about ASD following participation in a clinical education experience through the HCAA with adults on the autism spectrum. Qualitative methods were used to explore the findings in more depth and to gain a nuanced understanding of the clinical experience and its broader impact on the student clinicians (i.e., in terms of self-perceived changes in knowledge about ASD, self-efficacy as service providers for adults with ASD, openness to adults with ASD, and additional contact with adults with ASD).

Quantitative data were collected three times: (1) At the start of the fall semester, prior to the start of clinical experiences; (2) between the fall and spring semesters; and (3) at the end of the spring semester. Qualitative data were collected at time points 2 and 3 only, following student clinicians' HCAA experiences.

Participants. Student clinicians assigned to a HCAA placement were invited to participate in the study early in the fall semester. Participation began with informed consent (as approved by the university's Institutional Review Board), which explicitly stated that students could withdraw from or refuse to participate in the study at any time without affecting their grades or any other aspect of their 
program. All consented student clinicians $(n=17)$ were assigned an identification number to keep their data confidential.

Demographic data were collected through an online survey. Participating student clinicians were female and ranged in age from 22-31 years, with 16 student clinicians identifying their race as Caucasian, and one as African-American (no student clinicians identified themselves as Hispanic). Student clinicians had earned at least a bachelor's degree as a prerequisite for acceptance into the master's program in SLP, with one also holding a master's degree in another field. The majority earned prior degrees in SLP $(n=13)$, with the remaining students earning degrees in related fields, including education $(n=1)$, cognitive science $(n=1)$, psychology $(n=1)$, and behavioral sciences $(n=1)$.

Measures. The Autism Knowledge Survey-Revised (AKS-R; Swiezy, Fairbanks, Stuart, Ashby, Ables \& Stone, 2005) was used to measure student clinicians' knowledge about ASD for the quantitative portion of the study. The $A K S-R$ is a 20 -item survey that measures degree of agreement with statements addressing a variety of topics about ASD, including etiology, intervention, diagnosis, and outcomes. Student clinicians were asked to rate their agreement with each statement on a 6-point scale ( $1=$ Fully Agree with statement; $6=$ Fully Disagree with statement). A mean knowledge score was calculated, and responses were compared to model or 'correct' responses. Items were reverse scored as needed, such that a higher score on each statement reflected a higher level of knowledge. Students completed the survey individually through an electronic platform using their confidential personal identification number.

A five-item, open-ended questionnaire (see Appendix) was used to collect qualitative data regarding students' knowledge, confidence, and openness as related to adults on the autism spectrum. The survey asked students to describe their overall experience at the HCAA, including their quality and quantity of contact with adults on the autism spectrum. Student clinicians were asked to write a one to two paragraph response to each item using word processing software.

Data Analysis. Descriptive statistics were used to characterize the participant sample. A quantitative analysis of change across semesters in knowledge scores was carried out using a mixed-effects analysis of variance (ANOVA) procedure. Knowledge scores obtained from the $A K S-R$ represented the dependent variable, with time representing the within-subjects factor (with 3 levels for the 3 time points), and semester of HCAA experience serving as the between subjects variable (with 2 levels - first semester or second semester). The within-subject time effect and semester-by-time interaction were considered primary, as they 
tested whether or not the indices changed over time and whether or not change over time depended on the semester in which they received the training, respectively.

Qualitative analysis was used to analyze the narratives collected from SLP graduate students following their HCAA experiences. Two research assistants trained in qualitative coding methods independently evaluated each of the narratives to identify recurrent themes using a six-phase, thematic analysis procedure outlined by Braun and Clarke (2006). This analytical methodology was selected because it allowed the researchers to focus on examining and describing the students' experiences through their responses to specific questions that reflected the authors' research aims. In addition, thematic analysis methods have been utilized effectively by researchers in the field of ASD (e.g., Timmons, Ekas, \& Johnson, 2017) and SLP professional preparation (e.g., Finch, Fleming, Brown, Lethlean, Cameron, \& McPhail, 2013), among many others.

According to Braun and Clarke (2006), following familiarization with the data (phase 1), the second phase of this approach to thematic analysis (i.e., initial coding) involved evaluating the narratives line by line in order to identify and describe the ideas reported by the students. Codes were then assigned to units of data that appeared to be meaningful or significant. Data were consistently compared throughout the process in order to find similarities and differences in the responses, and to revise codes as needed. In the third phase of analysis (i.e., searching for themes), the coders focused on synthesizing larger segments of the data by identifying recurring concepts. These concepts were analyzed for similarities and grouped accordingly. In the fourth phase (i.e., reviewing themes), themes were reviewed and organized and the relationships between themes were analyzed in order to create core themes. During this fourth phase, a thematic map (i.e., visual representation of themes and overlap) was finalized and is presented in Results. The fifth phase (i.e., defining and naming themes) involved determining any subthemes within core themes and identifying the essence of each theme by locating examples from the student clinicians' responses. The sixth and final phase (i.e., producing the report) included organizing the themes and examples into a narrative that best described the data - this narrative is presented in the Results section.

In order to increase the rigor and decrease the subjectivity of the qualitative analysis methods used (as suggested by Barbour, 2001), the two independent coders compared codes as a form of "inter-rater reliability". During this process, the coders reviewed their proposed core themes and subthemes in order to identify any inconsistencies. The coders were found to be in agreement regarding all core 
themes. Subthemes that were identified by only one coder were discussed and either removed or, where appropriate, merged with an existing, agreed upon theme. In the final step, wording of themes and subthemes was refined by the study team to best represent the data and the student clinicians' expressed views.

\section{Results}

Quantitative Results. Using the mixed-effects ANOVA procedure, ASD knowledge (based on $A K S-R$ scores) demonstrated a statistically significant time effect, $F(2,20)=14.56, p<.0001$ [sphericity assumed], partial eta squared $=$ .593 , such that knowledge increased significantly over time. In addition, based on the significant statistical interaction between semester and time $[F(2,20)=3.89, p$ $=.037$, sphericity assumed, partial eta squared $=.28$ ], the timing of this knowledge gain depended on which semester the student clinician participated in the HCAA program. Specifically, as illustrated in Figure 1, knowledge increased from the beginning to the end of the first semester for those student clinicians who participated in a HCAA program during that time, but not for student clinicians who participated during the subsequent semester. For the student clinicians who participated in a HCAA program during the second semester, the improvement in knowledge only occurred between the beginning and end of the second semester.

Figure 1. ANOVA Results 


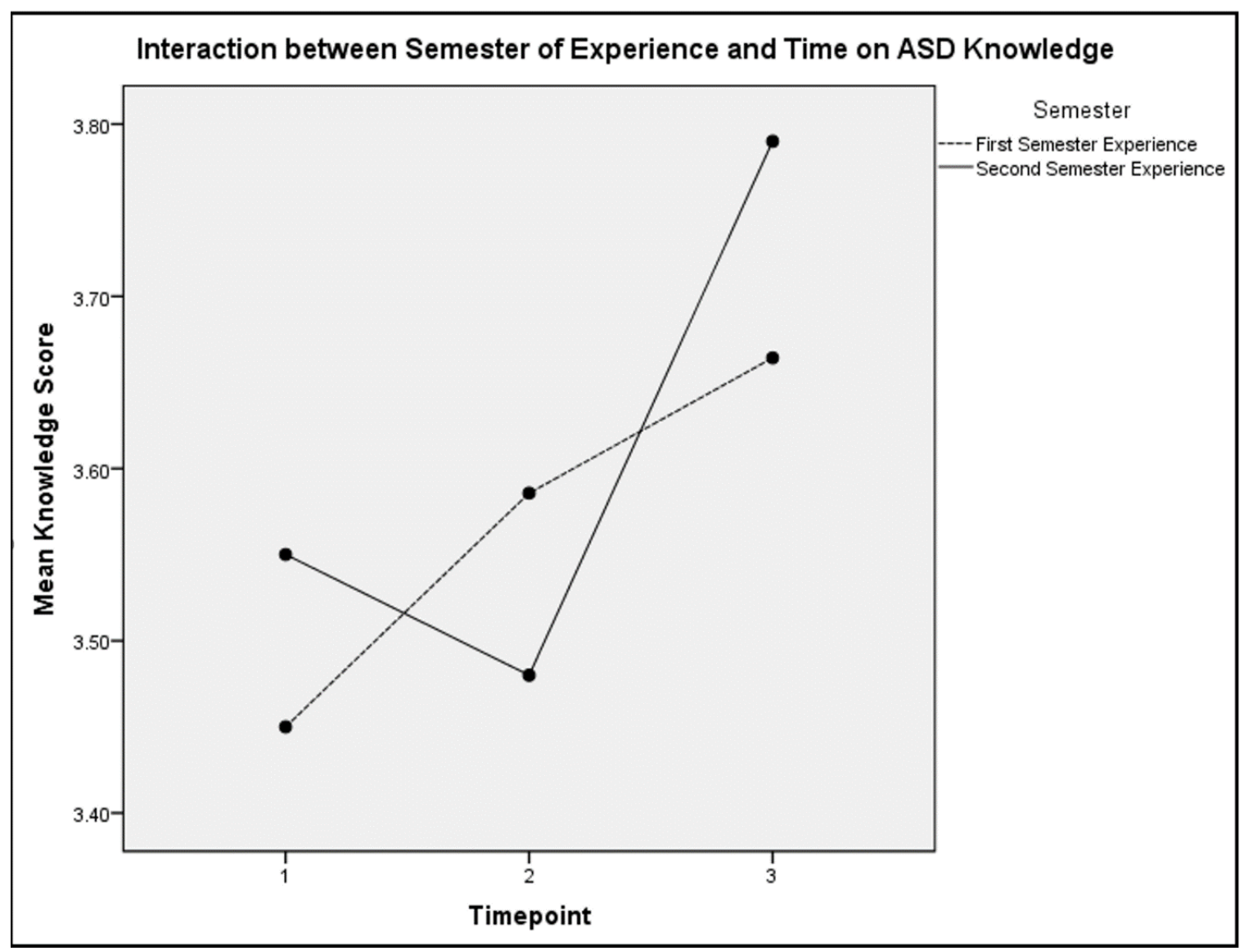

Note. (Mean[SD]) for each group are as follows: First Semester Timepoint 1 (3.45[.252]), Timepoint 2 (3.59[.219]), and Timepoint 3 (3.66[.182]); and Second Semester Timepoint 1 (3.55[.352]), Timepoint 2 (3.48)[.182]), and Timepoint 3 (3.79[.263])

Qualitative Findings. Qualitative data provided more in-depth findings about the student clinicians' experiences of working with adults with ASD. Analysis of the open-ended responses resulted in four core themes directly related to the topics addressed in the questionnaire: structure of the high-quality clinical experience, clinical knowledge about ASD, increased confidence, and increased openness. Several subthemes also emerged within two of the core themes.

The core themes and subthemes that emerged from analysis of the narrative data are summarized below and in Table 1. Quotations taken directly from the openended responses are used to provide examples to illustrate the identified themes and to more fully represent the breadth and depth within each theme. Analysis of thematic overlap across the open-ended responses suggests a meaningful 
relationship between the core themes. This relationship is presented in Figure 2 and summarized within the narrative below.

Table 1. Number of Respondents Reporting Each Theme and Subtheme

\begin{tabular}{|l|l|}
\hline Themes and Subthemes & $\begin{array}{l}\text { Number of } \\
\text { Respondents (\% of } \\
\text { total respondents) }\end{array}$ \\
\hline Structure of the clinical experience & $11(65 \%)$ \\
\hline Rewarding and high-quality experience & $8(47 \%)$ \\
\hline Opportunity to interact with multiple participants & $6(35 \%)$ \\
\hline Collaboration with other students and professionals & $17(100 \%)$ \\
\hline Clinical knowledge about ASD & $9(53 \%)$ \\
\hline Increase in clinical knowledge & $7(41 \%)$ \\
\hline Understanding of ASD as a spectrum & $7(41 \%)$ \\
\hline Understanding of what ASD looks like in adulthood \\
\hline Clinical skills & $12(71 \%)$ \\
\hline Confidence level & $7(41 \%)$ \\
\hline Increased confidence in serving & $6(35 \%)$ \\
\hline Openness & \\
\hline Increased openness to adults on the autism spectrum & $\begin{array}{l}\text { Open to working with adults on the spectrum prior to } \\
\text { placement }\end{array}$ \\
\hline
\end{tabular}


Figure 2. Thematic Map of Qualitative Findings

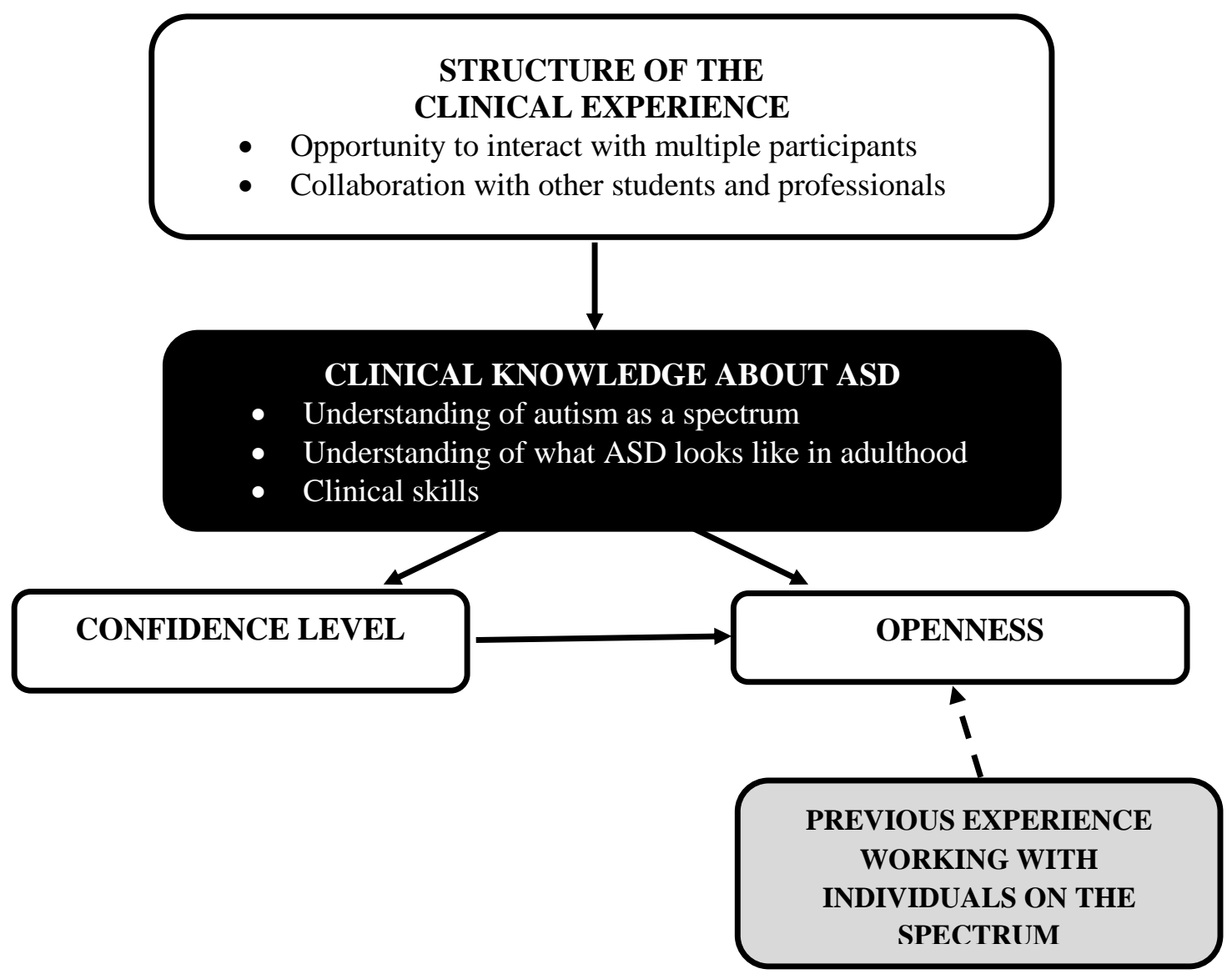

Structure of the clinical experience. In discussing the quality and quantity of contact with adults with ASD during their clinical placement, the majority of student clinicians $(n=11 ; 65 \%)$ described the placement as a rewarding and highquality experience. Students further defined specific aspects of the program that contributed to the quality of their experiences. These aspects are described below, with each defined as a subtheme.

Opportunity to interact with multiple participants. In their open-ended responses, many students $(n=8 ; 47 \%)$ highlighted the importance of having the opportunity to interact with multiple adults on the autism spectrum during their placement. Students described the group structure of the program as a strength and identified specific benefits of interacting with more than one client. In particular, engaging with multiple clients exposed them to a variety of participant strengths, needs, and interests. For example, one student wrote: "The participants of the HCAA 
program were all very different and presented with different needs and interests, which provided me with the opportunity to see how adults with autism differ." Another shared: "I feel that I truly got the experience to get to know each member of the group individually and that it gave me a great view of many different adults on the spectrum." Similarly, one student felt "...that working in a group enabled [them] to engage with a variety of adults with different skills and levels of communication abilities."

The group setting also provided students with a variety of types of interactions with participants, as one student reflected: "Since each of the participants ranged in their own personalities, ages, circumstances, and levels on the spectrum, each day included various interactions. These included intense situations, challenging discussions, inspiring improvements, etc."

Collaboration with other students and professionals. When writing about the quality of the program, several student clinicians $(n=6 ; 35 \%)$ also noted that the group structure afforded them the opportunity to collaborate with their fellow student clinicians and with other professionals (e.g., clinical supervisor, program staff). Direct support from supervisors and collaboration with peers enhanced the overall quality of the clinical experience. Reflecting this point, one student wrote: "I was able to learn from the HCAA supervisor and my own supervisor how to handle behavioral situations. I learned strategies to refocus attention, understand when the participant needed a break, and to help better develop reading skills through visualization." Another student wrote: "I liked the group format, as it gave me an opportunity to interact with more than just my two clients and to collaborate and learn with other students." Yet another student endorsed the effectiveness of the training model, remarking: "This program was enjoyable, naturalistic and overall, a great opportunity for clinicians, mentors, and participants to learn from and with one another."

Clinical knowledge about ASD. In discussing the knowledge gained through their clinical placements with adults on the autism spectrum, all student clinicians $(\mathrm{n}=17 ; 100 \%)$ noted that their clinical knowledge about ASD had increased. The students wrote about changes in their knowledge about ASD in general and, more specifically, about ASD in adulthood. They also discussed improved knowledge of clinical skills and strategies for meeting the needs of adults with ASD.

Understanding of ASD as a spectrum. Many students (n=9; 53\%) wrote about changes in their understanding of ASD as a spectrum following the placement. They described an improved understanding about the range of skills, abilities, and needs among individuals with ASD, with one student writing: "I learned so much 
from the HCAA experience, the participants, and supervisors. First of all and most importantly, it reinforced the notion that 'if you've met one person with autism, you've met one person with autism.' Each participant was so unique." Students related their change in knowledge to the group structure of the program. They explained that having an opportunity to interact with multiple adults on the autism spectrum helped them recognize that each individual on the autism spectrum presents with a unique set of strengths and needs. Another student emphasized this point: "Our group consisted of ten adults, all who had the diagnosis of autism but all were so different from one another. This really brought me more awareness and sensitivity for people on the spectrum."

Understanding of what ASD looks like in adulthood. Many student clinicians $(\mathrm{n}=7 ; 41 \%)$ also discussed an increased understanding of the specific needs of adults on the autism spectrum. They wrote in particular about the participants' social-communication needs, and how these needs impact their daily lives, with one student noting: "During each group session, we discussed different social needs that impact the participants' daily social interactions. The topics helped me understand what I can do as an SLP to help adults with autism overcome their social needs." Another student commented: "I learned a lot about their daily challenges, such as discrimination in the workplace and difficult social situations they encounter. I learned about areas of communication they have difficulty with such as turn taking during a conversation and initiating conversations." Students also talked about an improved understanding of the goals that adults with ASD set for themselves, with comments such as: "Working with adults on the spectrum taught me a lot about how decision making, self-regulation, and self-expression can develop throughout the years" and "I learned that most of the participants have aspirations and dreams of typically developing peers. Most of them want to get their driver's licenses, attend college, and obtain jobs. This was really eye opening to me."

Clinical skills. When writing about their changes in knowledge, many students $(\mathrm{n}=7 ; 41 \%)$ also talked about gaining a variety of clinical skills for working with adults on the autism spectrum. For example, one student wrote: "I learned skills throughout the semester that helped to address many of the needs of the adults in our group. I will carry these skills with me into many other settings and opportunities I have when working with adults." Student clinicians also reported learning to see the adult participants as peers and collaborators in the clinical process. They learned to treat the participants like adults by supporting their independence and inviting them to be equal participants in the intervention process. One student commented: "Working with adults is very different and it is important to remember that these participants are around the same age as me. We 
need to encourage independence through a respectful and adult tone of voice." In addition, another student wrote of learning "...to treat the participants as adults and to consult them on what they would like to do and what they would like to improve. I learned to explain the reason why we are working on activities and stress their progress."

Relatedly, students gained more specific clinical skills and strategies for working with this population, including providing participants with visual supports and tailoring interventions in order to meet individual and age-specific needs. For example, students wrote: "I learned the effectiveness of using visual instruction with individuals with ASD and made a habit of implementing it into therapy" and "It was also difficult at times to develop therapy ideas that were age and developmentally appropriate for the entire group while meeting the needs of everyone within the group. Being a part of this placement really taught me how to do those things." Further describing their skill development in terms of awareness of the range of presentations in individuals with ASD, one student wrote: "This experience taught me how differently ASD presents in individuals diagnosed, which helped me to develop the skills necessary to provide and structure differentiated and individualized therapy to target the varying needs of all the participants."

Confidence level. When asked about changes in their feelings of self-efficacy, or confidence, following the placement, the majority of students $(n=12 ; 71 \%)$ reported feeling more confident in their abilities to serve adults on the autism spectrum. For example, students wrote: "Following this program, I feel more confident in my ability to interact with and provide effective therapy to adults with ASD" and "Before this placement, I was nervous and unsure how to interact with people with autism. This program allowed me to become more comfortable and knowledgeable in the area." As seen in previous responses, students again highlighted the group structure of the program as a strength. They explained that working with multiple participants contributed to their increased confidence, with one student noting: "Having such a wide array of individuals to work with really helped me to gain more knowledge and develop more confidence in my abilities when working with people with autism."

Students also wrote about an increase in knowledge and skills as contributing to their improved sense of confidence in working with adults on the autism spectrum, writing "I feel more confident in my skills to serve adults on the autism spectrum. I have been provided with many techniques and resources for activities, managing behaviors and learning style" and "This learning experience has given me a greater sense of self-efficacy in terms of selecting appropriate goals and 
targeting them as a team with my client. I also learned that with adults, especially in a group setting, there are ways to become a social skills facilitator rather than a direct teacher."

Finally, for some students, the placement led to an increased interest in working with adults on the autism spectrum in the future. For example, one student wrote: "I am eager to learn more about the autistic population and work with individuals that are on the spectrum. This program has sparked an interest for autism in me. It is now an area in which I consider working."

Openness. Many of the students $(n=7 ; 41 \%)$ reported that their experience in the program led to an increase in openness to adults on the autism spectrum. One student noted: "I am much more open when interacting with adults on the spectrum after participating in the HCAA placement this semester." A link between this change in openness and an increase in knowledge, skills, and/or confidence was noted in their responses, with students making such comments as: "I definitely feel much more open and confident with adults on the spectrum. My own client and the others in the HCAA program aided in my own development of confidence and understanding of adults on the spectrum," and "I feel comfortable to interact with adults with autism and I do not shy away from conversations like before. I feel like I have a better understanding of the population and this has led me to have more interest in working with them."

In contrast, several students $(n=6 ; 35 \%)$ indicated that they did not have any change in openness because they already felt open to working with adults on the autism spectrum prior to the placement. For example, one student noted: "Prior to my placement, I had multiple experiences interacting and providing services to children and adults on the spectrum. These prior experiences allowed me to gain the openness required to successfully work with adults and children on the spectrum."

\section{Discussion}

A significant barrier to ASD-specific pre-professional training is the generalist nature of graduate programs in SLP (Donaldson, 2015). In order to graduate from an accredited master's program, a student must have met the standards for knowledge and skills related to the prevention, assessment, and intervention of communication and swallowing disorders and differences, from birth through adulthood, in areas as disparate as articulation, fluency, voice, language, hearing, and swallowing (Council for Clinical Certification in Audiology and SpeechLanguage Pathology of the ASHA, 2016). Graduate programs must provide students with the necessary breadth of coursework and experiences to meet these 
standards, while also giving them the depth of training required to become effective clinicians. This depth of training is of particular importance for serving individuals with ASD, given the heterogeneous nature of ASD and the wide variability of social, communication, behavioral, and sensory needs, among others (Barnhill, Polloway, \& Sumutka, 2010; Donaldson, 2015). This study responded to the limited information available to guide clinical training for SLPs who are increasingly likely to serve individuals with ASD across the lifespan.

Results from this study indicate that the particular clinical education experience provided by the HCAA was beneficial to student SLP clinicians in their preparation to work with adults with ASD. Not only did the study's findings indicate a measurable, quantitative impact of the experience on student clinicians' knowledge about ASD in general, but qualitative results provided overwhelmingly positive and informative insights into the broader impact of the experience. In sum, student clinicians described their increase in knowledge, openness, and confidence (or self-efficacy), especially highlighting the group aspect of the clinical experience as key to their growth. These findings mirror those from other fields wherein immersive, interactive experiences with individuals with a range of disabilities, including ASD, allowed professionals to enter the field with greater comfort, confidence, and acceptance (Park, et al., 2010; Shields \& Taylor, 2014).

The finding that student clinicians' factual knowledge about ASD increased following their HCAA experience may be related to the benefits of experiential or practical learning, with specific relation to the proposed potential for action (i.e., hands-on learning) in solidifying the learning process (Zull, 2002). In other words, the student clinicians may have gained the factual knowledge from various aspects of their educational experiences, including the HCAA experience, but findings suggest that the "action," or experience of interacting with the adults with ASD, may have impacted the solidification of that knowledge. This mirrors literature from the medical field, which often indicates experiential learning to be a key factor in furthering students' knowledge in their future area of practice (e.g., Eiser \& Connaughton-Storey, 2008). Further, aligning with Kolb and Kolb (2005), the HCAA experience may have increased student clinicians' openness to and self-efficacy in serving adults with ASD due to its focus on development of expertise through synergistic action and reflection. This conclusion reflects findings from other clinical fields, such as nursing, where research shows handson experiences such as clinical simulation increase students' feelings of selfefficacy prior to entering their clinical field (Akhu-Zaheya, Gharaibeh, \& Alostaz, 2013; Khalaila, 2014). 
Although the majority of students described their HCAA experience as highquality and rewarding, a few students provided suggestions for improvement. In particular, three students indicated that the group structure of the program detracted from their ability to address the participants' individual needs. They explained that because of the emphasis on whole-group activities, they felt that they did not have enough time to support participants making significant progress towards their individual goals. One student clinician also noted that she felt it was easier to plan for group activities and that she would have experienced more growth as a clinician if more individualized planning and intervention had been required. Those wishing to draw upon this work to guide development of clinical education programs may wish to incorporate this feedback by emphasizing a focus on group- and individual-based clinical training in ASD.

It is also important to note that despite reporting increased interest in and openness to interacting with adults with ASD, the majority of student clinicians indicated that they did not seek additional contact with adults with ASD (other than those served through their HCAA experience) outside of the HCAA over the course of the semester. Shields and Taylor (2014) note that students' change in attitude towards individuals with disabilities may not equate to a change in behavior. A similar possibility is suggested by the finding in the current study. Several students wrote about interacting with HCAA participants informally in the hallway or the waiting room; however, students added that their graduate school schedules did not afford them the time needed to engage in outside opportunities to interact with adults with ASD outside of their clinical experiences (e.g., adults in the community, adults met through volunteer opportunities, classmates in college courses). Next steps in this line of study include collection of follow-up data to determine students' trajectories and interactions with adults with ASD, both clinically and in the community, upon entry into the field.

\section{Limitations}

The generalizability of this study's findings is limited by the participants (i.e., student clinicians) being drawn from one university and one overarching clinical training program. Similarly, the results derived from the qualitative arm of the study require subsequent evaluation in a larger and novel sample to support their generalizability. In addition, between-group simple effects analyses to follow up on the significant interactions were not feasible given the sample size. Future research would benefit from a larger "N" to explore group differences further. Although the current study included a control condition by having two groups (i.e., those who received training in the first semester versus second semester), 
future work in this area would benefit from comparing the HCAA's program to alternative training programs.

Additional limitations were introduced through the qualitative and quantitative methods used. The specific (as opposed to more open-ended) nature of the qualitative questions posed to the student clinicians guided the responses and created pre-determined categories of responses simply through the questions' foci. Similarly, the specificity of the questions and lack of opportunity for follow-up to clarify responses limited the depth of analysis and perhaps even the possibility of comparison to other studies. In addition, the mode of response (i.e., online) for the questionnaire items used in the quantitative analyses introduced the possible limitation of participants consulting outside sources, although they were instructed to use their personal knowledge. Finally, although anonymity of feedback was ensured, there remains the possibility of bias in student clinicians' responses due to potential concerns about anonymity. Despite these limitations, the current study provides evidence to support the HCAA clinical education program's potential for serving as a model for other universities seeking to enhance preparation of future SLPs in their work with adults with ASD.

\section{Future Directions}

This study provides a first step in addressing the gap in research needed to inform clinical training models for pre-professional clinicians who are likely to serve individuals with ASD across the lifespan. The SLP field is in need of continued investigations in this area, with specific focus on identifying the key ingredients of successful training models and on determining the longitudinal impact of clinical and didactic training models on clinicians as they enter the field. Some research questions to address in the latter area include: Do practicing SLPs continue to evidence greater knowledge regarding ASD (e.g., diagnostic criteria, intervention) following engagement in specific clinical training models? Are practicing SLPs who engage in these clinical training models more likely to elect employment in settings where they will serve individuals, adults specifically, with ASD? Once SLPs enter the field, what do they realize was lacking in their clinical ASD training? Study of this area is in its infancy, but its importance is tantamount to the continued positive intervention experiences of individuals with ASD across the lifespan and to society's work towards greater acceptance and respect for difference. 


\section{References}

Akhu-Zaheya, L.M., Gharaibeh, M.K., \& Alostaz, Z.M. (2013). Effectiveness of simulation on knowledge acquisition, knowledge retention, and selfefficacy of nursing students in Jordan. Clinical Simulation in Nursing, 9(9), e335-e342. doi: http://dx.doi.org/10.1016/j.ecns.2012.05.001

American Speech-Language-Hearing Association (n.d.). Autism (Practice Portal). Retrieved May 16, 2017, from http://www.asha.org/PRPSpecificTopic.aspx ?folderid=8589935303\&secti on $=$ Resources

Baio, J. (2014). Developmental Disabilities Monitoring Network Surveillance Year 2010 Principal Investigators; Centers for Disease Control and Prevention (CDC). Prevalence of autism spectrum disorder among children aged 8 years-Autism and developmental disabilities monitoring network, 11 sites, United States, 2010. Morbidity and Mortality Weekly Report Surveillance Summaries, 63, 1-21.

Barbour, R. S. (2001). Checklists for improving rigour in qualitative research: A case of the tail wagging the dog? British Medical Journal, 322(7294), 1115-1117.

Barnhill, G. P., Polloway, E. A., \& Sumutka, B. M. (2010). A survey of personnel preparation practices in autism spectrum disorders. Focus on Autism and Other Developmental Disorders, 26(2), 75-86.

Braun, V. \& Clarke, V. (2006). Using thematic analysis in psychology. Qualitative Research in Psychology, 3(2), 77-101.

Council for Clinical Certification in Audiology and Speech-Language Pathology of the American Speech-Language-Hearing Association. (2016). 2014 Standards for the Certificate of Clinical Competence in Speech-Language Pathology. Retrieved from http://www.asha.org/Certification/2014Speech-Language-Pathology-Certification-Standards/.

Donaldson, A. L. (2015). Pre-professional training for serving children with ASD: An apprenticeship model of supervision. Teacher Education and Special Education: The Journal of the Teacher Education Division of the Council for Exceptional Children, 38(1), 58-70.

Eaves, L. C., \& Ho, H. H. (2008). Young adult outcome of autism spectrum disorders. Journal of Autism and Developmental Disorders, 38(4), 739747.

Eiser, A. R., \& Connaughton-Storey, J. (2008). Experiential learning of systemsbased practice: A hands-on experience for first-year medical residents. Academic medicine, 83(10), 916-923.

Finch, E., Fleming, J., Brown, K., Lethlean, J., Cameron, A., \& McPhail, S. M. (2013). The confidence of speech-language pathology students regarding 
communicating with people with aphasia. BMC Medical Education, 13(1), 92.

Freedman, S. E. (2014). Knowledge of Autism Spectrum Disorder among College Students in Health Care Disciplines. Perspectives on Issues in Higher Education, 17(1), 17-26.

Gillespie-Lynch, K., Brooks, P. J., Someki, F., Obeid, R., Shane-Simpson, C., Kapp, S. K. ... \& Smith, D. S. (2015). Changing college students' conceptions of autism: An online training to increase knowledge and decrease stigma. Journal of Autism and Developmental Disorders, 1-14.

Glogowska, M. (2011). Paradigms, pragmatism and possibilities: mixed-methods research in speech and language therapy. International Journal of Language and Communication Disorders, 46(3), 251-260. doi: 10.3109/13682822.2010.507614.

Gotham, K., Marvin, A. R., Taylor, J. L., Warren, Z., Anderson, C. M., Law, P. A., \& ... Lipkin, P. H. (2015). Characterizing the daily life, needs, and priorities of adults with autism spectrum disorder from Interactive Autism Network data. Autism: The International Journal of Research \& Practice, 19(7), 794-804.

Hartley-McAndrew, M., Doody, K. R., \& Mertz, J. (2014). Knowledge of autism spectrum disorders in potential first-contact professionals. North American Journal of Medical Sciences, 7(3), 97-102.

Howlin, P., \& Moss, P. (2012). Adults with autism spectrum disorders. Canadian Journal of Psychiatry, 57(5), 275-283.

Jarvis, P. (2004). Adult education and lifelong learning: Theory and practice. New York, NY: Routledge.

Kanner, L. (1943). Autistic disturbances of affective contact. Nervous Child, 2, 217-250.

Khalaila, R. (2014). Simulation in nursing education: an evaluation of students' outcomes at their first clinical practice combined with simulations. Nurse Education Today, 34(2), 252-258.

Kolb, A. Y., \& Kolb, D. A. (2005). Learning styles and learning spaces: Enhancing experiential learning in higher education. Academy of Management Learning \& Education, 4(2), 193-212.

Kolb, A. Y., \& Kolb, D. A. (2009). The learning way meta-cognitive aspects of experiential learning. Simulation \& Gaming, 40(3), 297-327.

Loveland, K. A., \& Kelley, M. L. (1988). Development of adaptive behavior in adolescents and young adults with autism and Down syndrome. American Journal of Mental Retardation, 93(1), 84-92.

Orsmond, G., Shattuck, P., Cooper, B., Sterzing, P., \& Anderson, K. (2013). Social participation among young adults with an autism spectrum disorder. 
Journal of Autism \& Developmental Disorders, 43(11), 2710-2719. doi:10.1007/s10803-013-1833-8

Park, M., Chitiyo, M., \& Choi, Y. (2010). Examining pre-service teachers' attitudes towards children with autism in the USA. Journal of Research in Special Educational Needs, 10(2), 107-114. doi:10.1111/j.14713802.2010.01150.x

Plumb, A. M. \& Plexico, L. W. (2013). Autism spectrum disorders: Experience, training, and confidence levels of school-based speech-language pathologists. Language, Speech, and Hearing Services in Schools, 44(1), 89-104.

Price, J. R. (2013). Preservice knowledge and training in autism spectrum disorders. SIG 10 Perspectives on Issues in Higher Education, 16(2), 7180.

Roux, A. M., Shattuck, P. T., Rast, J. E., Rava, J. A., \& Anderson, K. A. (2015). A national autism indicators report: Transition into young adulthood. Philadelphia, PA: Life Course Outcomes Research Program, A.J. Drexel Autism Institute, Drexel University.

Schwartz, H. \& Drager, K. D. (2008). Training and knowledge in autism among speech-language pathologists: A survey. Language, Speech, and Hearing Services in Schools, 39(1), 66-77.

Sheepway, L., Lincoln, M., \& Togher, L. (2011). An international study of clinical education practices in speech-language pathology. International Journal of Speech-Language Pathology, 13(2), 174-185. doi:10.3109/17549507.2011.491129

Shields, N. \& Taylor, N. F. (2014). Contact with young adults with disability led to a positive change in attitudes toward disability among physiotherapy students. Physiotherapy Canada, 66(3), 298-305. doi:10.3138/ptc.2013-61

Sivak, R. (2016, August 8). Helping autistic adults meet the challenges of life on the spectrum [Interview]. Retrieved from http://wypr.org/post/helpingautistic-adults-meet-challenges-life-spectrum\#stream/0

Swiezy, N., Fairbanks, J., Stuart, M., Ashby, I., Ables, E. M., \& Stone, W. (2005). Autism knowledge survey. Christian Sarkine Autism Treatment Center, HANDS in Autism.

Timmons, L., Ekas, N. V., \& Johnson, P. (2017). Thankful thinking: A thematic analysis of gratitude letters by mothers of children with autism spectrum disorder. Research in Autism Spectrum Disorders, 34, 19-27.

Turcotte, P., Mathew, M., Shea, L., Brusilovskiy, E., \& Nonnemacher, S. (2016). Service needs across the lifespan for individuals with autism. Journal of Autism \& Developmental Disorders, 46(7), 2480-2489.

Zull, J. E. (2002). The art of changing the brain: Enriching teaching by exploring the biology of learning. Stylus Publishing, LLC. 
Teaching and Learning in Communication Sciences \& Disorders, Vol. 1 [2017], Iss. 2, Art. 5

https://ir.library.illinoisstate.edu/tlcsd/vol1/iss2/5 


\section{Appendix. Qualitative questionnaire items}

(1) Write about the quantity and quality of your contact with adults on the autism spectrum through your HCAA placement this semester.

(2) Write about any knowledge you gained through your HCAA placement this semester regarding autism in general and autism in adulthood.

(3) Write about any changes in your feelings of self-efficacy about serving adults on the autism spectrum after your HCAA placement this semester.

(4) Write about any changes in your openness to adults on the autism spectrum following your HCAA placement this semester.

(5) Write about any additional contact with adults on the autism spectrum you sought outside of assigned clinical experiences this semester. 